\title{
A representação
social da Psicologia e do Psicólogo
}

\section{Maria Alice Vanzolini da Silva Leme, Vera Silvia Raad Bussab e Emma Otta}

\section{Instituto de Psicologia}

Universidade de Sáo Paulo

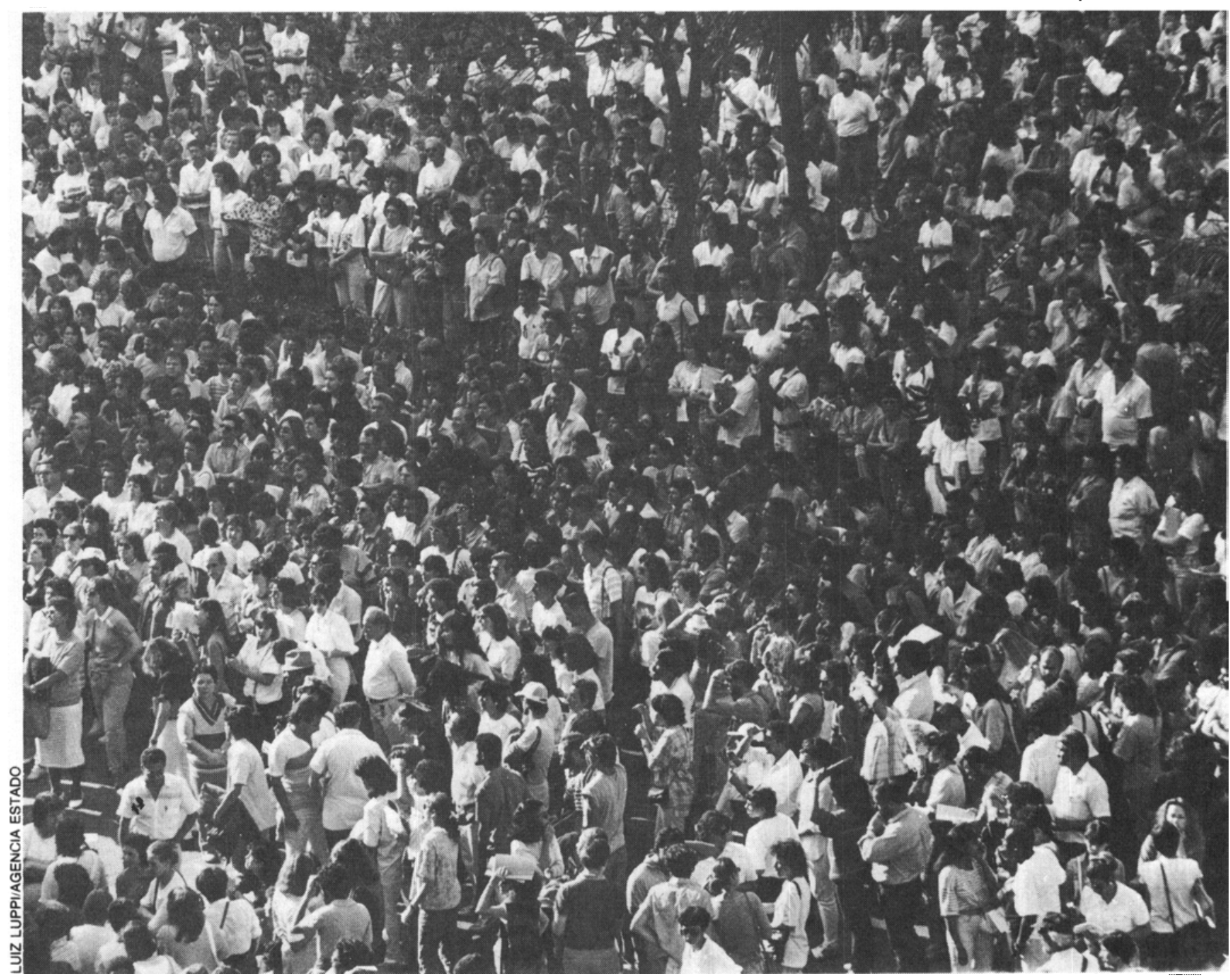

7 ste trabalho é uma tentativa L de estabelecer qual é a re1 logia e/ou do psicólogo, que circula em um certo segmento da população da cidade de São Paulo. O veículo dessa representação foram alunos ingressantes em um curso de Psicologia, que responderam a seguinte pergunta: "Qual é, a seu ver, a imagem que o público leigo tem do psicólogo?" Partiu-se do pressuposto que este seria um bom veículo, na medida em que, tendo recentemente feito uma opção de carreira, teriam sido alvo de muitos comentários a respeito.

O conceito de representação social aqui utilizado é de Moscovici que, em 1976, publicou seu trabalho sobre a representaçăo social da Psicanálise na PSICOLOGIA, CIÉNCIA E PROFISSÃO, 29 
França. A leitura de Moscovici nos forneceu um referencial teórico que julgamos bastante adequado para lidar com a pergunta acima citada, proveniente de um questionário amplo, cujos dados eram utilizados para discussão, em classe, de problemas metodológicos de pesquisa e da profissão do psicólogo, desde 1976 até 1984.

Representação social é um conjunto de conceitos, explicaçōes e afirmações que se originam na vida diária, no curso de comunicaçōes interindividuais (Moscovici, 1981). É a versão contemporânea do senso comum. Vejamos o porquê. A maior parte dos objetos, conceitos, analogias que se impōem ao nosso entendimento, nos dias de hoje, é produto de pesquisa científica. Constituem uma massa enorme de conhecimentos que nos di.zem respeito, mas que não estāo ligados à nossa experiência direta. Pensamos e vemos por procuração. Grupos competentes são encarregados de obtê-los e transmiti-los. Temos que elaborar um novo senso comum a partir de elementos provenientes de um universo do qual não participamos, que tem uma linguagem e uma lógica que não são as do nosso universo cotidiano. Este é o universo das representações sociais, o universo consensual. $O$ da ciência, no que nos diz respeito, é um universo reificado.

Toda representação social recorta e simboliza atos e situações que se tornam ou nos são comuns. Não deve ser vista de um modo passivo, como reflexo na consciência de um objeto ou conjunto de idéias, mas de um modo ativo: como uma reconstrução do dado em um contexto de valores, reaçōes, regras com o qual se torna solidário. A linguagem o traz para o fluxo das associaçōes, o investe de metáforas, o projeta no espaço simbólico.

Toda representação tende a tornar familiar o não familiar. $\mathrm{Na}$ dinâmica da familiarização, os objetos e eventos são reconhecidos, compreendidos com base em encontros anteriores, em modelos. Aqui a memória predomina sobre a lógica, o passado sobre o presente, a resposta sobre o estímulo. $O$ ato de re-presentação transfere o que é estranho, perturbador do universo exterior para o interior, coloca30 PSICOLOGIA, CIÊNCIA E PROFISSÃO o em uma categoria e contexto conhecidos. Neste universo consensual, o veredicto precede o julgamento.

A ciência segue um caminho inverso, principalmente no nível lógico: vai das premissas às conclusões. Isto parece ser tão ao arrepio do que fazemos espontaneamente que todo um aparato de lógica e de prova é recrutado para ir contra esta tendência de tornar o nāo-familiar, familiar. Muito pelo contrário, a ciência torna o familiar, não-familiar.

Moscovici (1976) propōe dois processos que são importantes nesta forma de pensamento em que predominam a memória e as conclusōes preestabelecidas: a ancoragem e a objetivação. Ancorar é trazer para categorias e imagens conhecidas o que não está ainda classificado e rotulado. "Tudo o que permanece inclassificável e não rotulável parece nãoexistente, estranho e, assim, ameaçador... Realmente, representação é basicamente um processo de classificação e nomeação, um método de estabelecer relaçóes entre categorias e rótulos" (Moscovici, 1981, p. 193, grifos no original). Objetivar é transformar uma abstração em algo quase físico.

O rótulo confere uma afiliação e uma posição na matriz cultural de identidades. $\mathrm{O}$ anônimo não é passível de ser convertido em uma imagem comunicável. Quando classificamos e rotulamos estamos também atribuindo um valor positivo ou negativo e uma posição em uma ordem hierárquica. Classificar alguém como neurótico, pobre, subversivo, não é meramente afirmar um fato. Está se fazen. do um julgamento que revela uma "teoria" sobre a sociedade e a natureza humana. Uma categoria oferece um modelo, um protótipo que a expressa e fornece uma espécie de retrato-robot dos indivíduos que pertencem a ela. Ao categorizar alguém, escolhemos um dentre os protótipos que temos guardados em nossa memória e estabelecemos uma relação positiva ou negativa com ele. A descrição deste processo ilustra o significado de se dizer que, no mundo das representações, o veredicto tem precedência sobre o julgamento.

$\mathrm{Na}$ avaliação da evidência disponível, temos que tomar uma decisão: ou aproximamos o caso do protótipo, generalizando, ou aumentamos a distância, individualizando. Esta decisão não é puramente intelectual, expressa uma atitude para com a pessoa ou coisa e um desejo de vê-la como normal ou desviante.

A objetivação significa descobrir o aspecto icônico de uma idéia ou ser, parear o conceito com uma imagem. Por exemplo, comparar Deus a um pai (o psicólogo é comparado a um pai...de...santo...).

As proposiçōes, reações, avaliaçōes que constituem as representações estão organizadas de modo diverso segundo as culturas, classes, grupos sociais e constituem tantos universos quantos são estes últimos.

Cada universo pode ser visto sob três dimensōes: a) informação, b) atitude ou valoração, c) campo de representação ou imagem. A informação tem a ver com a organização dos conhecimentos que um grupo possui a respeito de um objeto social. A informação pode ser completa ou incom. pleta, coerente ou incoerente. A atitude destaca a orientação global em relação ao objeto de representação social: favorável, desfavorável, neutra. O campo de representação remete-nos à idéia de imagem de modelo social, ao conteúdo concreto e limitado de um aspecto preciso do objeto de representação. Foram estas as dimensões que procuramos estabelecer nas respostas de nossos sujeitos.

\section{Mótodo}

SUJEITOS. Participaram da pesquisa 556 alunos ingressantes em um curso de Psicologia da cidade de São Paulo.

MATERIAL. Cada aluno recebeu, no primeiro dia de aula, um questionário mimeografado, com vinte perguntas, que respondeu por escrito. Nesta pesquisa, analisamos as respostas à pergunta: "Qual é, a seu ver, a imagem que o público leigo tem do psicólogo?"

PROCEDIMENTO. As respostas coletadas entre os anos de 1976 e 1984 foram submetidas a uma análise de conteúdo, realizada em conjunto pelas três autoras deste estudo. Procurou-se esgotar, em cada uma, todos os conteúdos referentes às três dimensōes investigadas. Ilustraremos esta 
análise examinando a resposta dada por um aluno, "Secretário de Psiquiatra":

a) Presença ou ausência de informaçōes sobre a profissão. Em caso positivo, o tipo de informação foi categorizado. No exemplo "Secretário de Psiquiatra", a profissão é conhecida e a área de atuaçāo conhecida é a clínica.

b) Conotações de valor positivo ou negativo implicadas nos conteúdos. No exemplo em questão o valor é negativo, sendo a profissão desprestigiada em relação à medicina.

c) A dimensão campo de represen. tação foi analisada sob dois aspectos:

$\left.1^{\circ}\right)$ Tipos de comparações, aproximações ou mais propriamente ancoragens feitos em relação a categorias sociais conhecidas. No exemplo foi feita ancoragem na psiquiatria. Cabe notar que, nos casos de conhecimento de algum aspecto da profissão e ausência de ancoragem em qualquer outra categoria social conhecida, consideramos a ocorrência de ancoragem na própria psicologia.

$2^{\circ}$ ) Concretização de aspectos do saber, do modo de atuação e da personalidade atribuídos ao psicólogo. No exemplo transparecem aspectos de saber menor e de incompetência do profissional em questão.

\section{Resultados}

\section{Nível de informação}

$\mathrm{Na}$ análise desta dimensão, foi possível identificar quatro categorias de respostas, que se encontram na Tabela 1:

a) Profissãoconhecida: englobou as respostas que demonstravam existir conhecimento acerca da psicologia e que foram, subsequientemente, classificadas segundo a referência feita a áreas de atuação: Psicologia clínica: "É um resolvedor de problemas de loucos"; "Uma pessoa que só de olhar ou conversar já sabe de seus problemas, pontos fracos e fortes $e$ como ajudar". Psicologia educacional: "Sinônimo de pedagogo". Psicologia do trabalho: "É aquele que trabalha em departamento de pessoal de alguma indústria".

Testes: "É um aplicador de testes".

Ciência: "Acho que não dão o devido valor a esta ciência, a meu ver, a mais importante de todas".

b) Profissões desconhecidas: " $O$ público não sabe ou não tem informaçāo sobre o que o psicólogo sabe fazer".
TABELA 1

DIMENSÃO DE INFORMAÇÃO SOBRE A PROFISSÃO DE PSICÓLOGO PORCENTAGEM DE RESPOSTAS

\begin{tabular}{|c|c|c|c|c|c|c|c|c|c|c|c|}
\hline \multicolumn{2}{|c|}{ INFORMAC̨ĀO } & 76 & 77 & 78 & 79 & 80 & 81 & 82 & 83 & 84 & TOTAL \\
\hline \multirow{5}{*}{ CONHECIDA } & CLINICA & 76 & 61 & 70 & 79 & 79 & \begin{tabular}{|l|l|}
66 \\
\end{tabular} & 57 & 68 & 53 & 67 \\
\hline & EDUCAÇĀO & 0 & 1 & 0 & 0 & 0 & \begin{tabular}{|l|}
0 \\
\end{tabular} & 1 & 2 & 0 & 1 \\
\hline & TRABALHO & $\dot{0}$ & 0 & 0 & 0 & 0 & 0 & 1 & 0 & 0 & 0 \\
\hline & TESTES & 0 & 1 & 3 & 0 & 0 & 0 & 0 & 0 & 2 & 1 \\
\hline & CIÊNCIA & 0 & 1 & 0 & 0 & 0 & 0 & 0 & 2 & 0 & 0 \\
\hline \multicolumn{2}{|c|}{ DESCONHECIDA } & 7 & 9 & 0 & 2 & 3 & 7 & 6 & 2 & 8 & 5 \\
\hline \multicolumn{2}{|c|}{$\begin{array}{l}\text { RESPOSTAS AMBIGUAS OU VALORATIVAS } \\
\text { SEM CONTEÚDO DE INFORMAÇÃO }\end{array}$} & 17 & 24 & 25 & 19 & 18 & 27 & 33 & 25 & 34 & 25 \\
\hline \multicolumn{2}{|l|}{ EM BRANCO } & 0 & 1 & 1 & 0 & 0 & 0 & 1 & 2 & 2 & 1 \\
\hline
\end{tabular}

TABELA 2

DIMENSÃO VALORATIVA: PORCENTAGEM DE RESPOSTAS

\begin{tabular}{|l|r|r|r|r|r|r|r|r|r|r|}
\hline VALORAÇÃO & 76 & 77 & 78 & 79 & 80 & 81 & 82 & 83 & 84 & TOTAL \\
\hline POSITIVA & 38 & 26 & 38 & 19 & 30 & 22 & 20 & 22 & 21 & 26 \\
\hline NEGATIVA & 60 & 73 & 62 & 74 & 70 & 78 & 80 & 78 & 79 & 73 \\
\hline NEUTRA & 2 & 1 & 0 & 6 & 0 & 0 & 0 & 0 & 0 & 1 \\
\hline
\end{tabular}

c) Respostas ambíguas ou valorativas, sem conteúdo de informação: "É uma figura ornamental"; "A mesma vișão que a minha".

d) respostas em branco.

Como se pode observar na Tabela 1. a profissão é bem mais conhecida do que desconhecida, mas conhecida, principalmente, como psicologia clí. nica.

A análise estatística 1 mostra que não houve nem aumento nem diminuição significativa desta tendência no tempo $(r=-0,53 ; t=-1,65)$.

Por outro lado, houve aumento significativo de respostas ambíguas ou valorativas, sem conteúdo de informação $(r=0,71 ; r=2,66)$.

\section{Atitude ou dimensão valorativa}

Procurou-se estabelecer se o conteúdo das respostas expressava valoração positiva, negativa ou neutralidade. A Tabela 2 mostra que $73 \%$ das respostas expressam uma valoração negativa, praticamente inexistindo a neutralidade.

$O$ teste estatístico revelou um cres. cimento significativo das valoraçōes negativas com o passar do tempo ( $\mathrm{r}=$ 0,$81 ; t=3,68$ ).

\section{Campo de representação ou imagem}

Duas sistematizaçōes possiveis feitas pelos sujeitos emergiram desta análise: uma que mostrava a aproximaçào do psicólogo de certas categotias sociais conhecidas, entre as quais identificaram-se a dos profissionais, a dos guias espirituais e a dos confiden. tes; a segunda referia-se a uma concretização da pessoa do psicólogo, com atribuiçōes de características relativas ao seu saber, modo de atuaçāo e personalidade. Estas características foram agrupadas segundo sua conotação positiva ou negativa.

$\mathrm{Na}$ Tabela 3 estão resumidos os resultados telativos à aproximação de

1 A anflise estatistica realizada com os dados julgador relevantes de todas as tabelas foi a mesma: calculou-se - coeficiente de correlaçäo entre as porcentagens e os anos; obtido o t, pastou-se ao cálculo do $t$, usando-se a fórmula

$$
r=(\text { ganus de liberdade })^{1 / 2}
$$

e comparou-se com t eritico-2,36S 7 graus de libetdade e $\mathrm{p} \cdot 0,05)$. A formula de $t$ t do programa SPSS (Statistical Program for Social Sciences). A hipotese nola foi de independéncia entre o julgamento e a data, isto $\hat{E}$, de estabilidade do julgamento no tempo. 
TABELA 3

DIMENSÃO CAMPO DE REPRESENTAÇĀO: PORCENTAGEM DE RESPOSTAS

\begin{tabular}{|l|l|c|c|c|c|c|c|c|c|c|c|}
\hline CATEGORIAS SOCIAIS & 76 & 77 & 78 & 79 & 80 & 81 & 82 & 83 & 84 & TOTAL \\
\hline \multirow{5}{*}{ PROFISSIONAIS } & PSICOLOGIA & 45 & 65 & 71 & 67 & 69 & 43 & 48 & 63 & 65 & 60 \\
\cline { 2 - 10 } & PSIQUIATRIA & 27 & 20 & 4 & 24 & 10 & 28 & 22 & 13 & 14 & 18 \\
\cline { 2 - 10 } & PSICANÁLISE & 3 & 2 & 16 & 2 & 2 & 4 & 4 & 6 & 8 & 5 \\
\cline { 2 - 11 } & INTELECTUAL & 3 & 0 & 0 & 0 & 0 & 0 & 2 & 0 & 8 & 2 \\
\cline { 2 - 11 } & PEDAGOGIA & 0 & 2 & 0 & 0 & 0 & 0 & 2 & 0 & 0 & 0 \\
\hline \multirow{3}{*}{ GUIAS ESPIRITUAIS } & PAI-DE-SANTO & 3 & 6 & 4 & 4 & 7 & 21 & 17 & 9 & 5 & 9 \\
\cline { 2 - 11 } & PADRE & 3 & 2 & 2 & 0 & 5 & 0 & 2 & 2 & 0 & 2 \\
\hline \multirow{5}{*}{ CONFIDENTES } & CONSELHEIRO & 0 & 2 & 2 & 0 & 5 & 2 & 2 & 0 & 0 & 2 \\
\cline { 2 - 11 } & PAI & 6 & 2 & 0 & 2 & 2 & 0 & 0 & 0 & 0 & 2 \\
\cline { 2 - 11 } & AMIGO & 9 & 0 & 0 & 2 & 0 & 2 & 0 & 6 & 0 & 2 \\
\cline { 2 - 11 } & BABA & 0 & 0 & 0 & 0 & 0 & 0 & 0 & 2 & 0 & 0 \\
\hline
\end{tabular}

categorias sociais conhecidas. Como se pode verificar, a maior incidência de respostas recai na aproximação em relação às profissōes $(85 \%)$, seguida pela dos guias espirituais $(11 \%) \mathrm{e}$, por último, pela dos confidentes (6\%).

Foi possível distinguir as seguintes categorias profissionais citadas nas respostas, algumas das quais estão representadas a seguir.

Fazem parte da categoria psicologia respostas do tipo: "O psicólogo éं " um profissional como outro qualquer" ou "o psicólogo contribui para a sociedade porque exerce uma profissão assistencial". Em termos de análise estatística, esta categoria apresentou estabilidade no tempo ( $\mathbf{r}=$ 0,$02 ; \mathbf{t}=0,05$ ).

A segunda aproximação mais importante é feita com a psiquiatria: "Médico de louco"; "Em geral o psicólogo é igual ao psiquiatra"; "Pra começo de conversa nem sabem que existe (pelo menos no interior) e freqüentemente confundem com o psiquiatra". Tambem aqui não se rejeitou a hipótese nula de estabilidade ( $r^{2}$ 0,$05 ; \mathrm{t}=0,15$ ).

Ainda estável no tempo $(n=0,09 ; t=$ $0,24)$ foi a aproximação da psıcologia à psicanálise, mas com um número de respostas bem menor que em relaçãc à psiquiatria. Exemplos típicos são: "A imagem de um paciente deitado no divãa, contando sua vida"; "Alguém menos louco do que ele, que tenha um divã onde ele possa se esquecer ou passar seus problemas". ria". Esta imagem tem estabilidade no tempo $(r=0,41 ; t=1,19)$. A aproximação do padre, bem menos freqüente que a anterior, surgiu em respostas como: "A mesma de um padre que dá conselhos, interfere na vida de seus fiéis pecadores". Não foi feita análise estatística.

A categoria confidentes reúne com igual frequiência as figuras do pai, do conselheiro e do amigo. Também foi registrada, embora com baixa freqüência, a figura babá. Exemplos: "Um conselheiro, prolongamento atual da imagem do pai"; "Amigo pago"; "Babá de louco".

Uma segunda sistematização foi feita, distinguindo os diferentes tipos de atribuição feitos pelos sujeitos a respeito do psicólogo. Serão apresentados, em primeiro lugar, os dados que refletem valoração negativa, por serem os mais freqüentes (Tabela 4), $e$, finalmente, dos dados que refletem valoração positiva, para que se possa terminar o trabalho com uma nota mais agradável (Tabela 5).

Conforme consta da Tabela 4, as descriçōes prendem-se a três aspectos: os relativos ao conhecimento de que dispöe o psicólogo, ou seja, o que sabe; os relacionados à sua prática, isto $\hat{\varepsilon}$, o que faz; os que mencionam características pessoais, dizendo-nos como é.

O conhecimento de que o psicólogo dispõe para exercer sua profissão

TABELA 4

DIMENSÃO CAMPO DE REPRESENTAÇÃO: PORCENTAGEM DE CONCEITUAÇÕES (OBJETIVACŌES) ASSOCIADAS A VALORACOOES NEGATIVAS

\begin{tabular}{|c|c|c|c|c|c|c|c|c|c|c|c|}
\hline \multicolumn{2}{|c|}{ Caracteristicas Negativas } & & Total \\
\hline \multirow{5}{*}{ 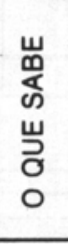 } & Incompetente & 30 & 47 & 28 & 30 & 31 & 33 & 35 & 40 & 7 & 37 \\
\hline & Elitista & 4 & 8 & 26 & 9 & 14 & 15 & 16 & 8 & 11 & 12 \\
\hline & Charlatão & 11 & 12 & 17 & 9 & 8 & 8 & 10 & 8 & 7 & 10 \\
\hline & Desacreditado & 4 & 4 & 3 & 2 & 6 & 8 & 12 & 10 & 5 & 6 \\
\hline & Amigo Pago & 0 & 0 & 0 & 4 & 0 & 0 & 0 & 6 & 2 & 1 \\
\hline \multirow{3}{*}{ 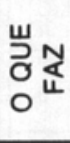 } & Invasor + Temor & 26 & 13 & 11 & 11 & 16 & 11 & 10 & 6 & 4 & 11 \\
\hline & Medo da Loucura & 15 & 2 & 8 & 4 & 4 & 0 & 4 & 2 & 4 & 4 \\
\hline & Manipulador+ Temor & 0 & 0 & 3 & 4 & 2 & 6 & 4 & 0 & 2 & 2 \\
\hline \multirow{4}{*}{$\begin{array}{l}\underset{w}{w} \\
\breve{\partial} \\
0\end{array}$} & Louco/Pirado & 11 & 9 & 6 & 26 & 12 & 19 & 8 & 16 & 11 & 13 \\
\hline & Chato & 0 & 0 & 0 & 0 & 2 & 0 & 2 & 0 & 4 & 1 \\
\hline & Desumano & 0 & 4 & 0 & 0 & 2 & 0 & 0 & 2 & 0 & 1 \\
\hline & Indeciso & 0 & 2 & 0 & 0 & 2 & 2 & 0 & 2 & 4 & 1 \\
\hline
\end{tabular}


foi transmitido por frases que expressam as idéias de incompetência, subciência, saber menor. Exemplos: "Uma imagem ruim, que os psicólogos não têm conhecimento para executar um trabalho sério"; "Um subprofissional"; "Secretário de psiquiatra". Foi encontrada estabilidade no tempo para esta categoria $(r=0,40 ; t$ $=1,16$.

Sob o rótulo elitista foram colocadas respostas que caracterizam o psicólogo como "Um profissional do blá, blá blá e, ainda por cima, atuando apenas com a elite"; "Alguém não tão necessário à sociedade, um capricho e privilégio de umas poucas pessoas"; "Uma frescura usada só por gente rica". Este conceito mostrou-se estável no tempo $(r=0,10 ; t=$ $0,27)$.

O emprego do rótulo charlatão traz à baila a idéia da cobrança ilegítima pelos serviços prestados: "Um charlatão, sem função eficaz para a sociedade"; "Radicalmente falando, um charlatão que cobra caro pelo' que aprendeu numa faculdade "fácil" "; "Não é muito boa. Eles a marginalizam demais, taxam os psicólogos como charlatães"; "Não resolve os problemas e tira o dinheiro dos outros". Esta categoria também é estável no tempo $(\mathrm{r}=0,64 ; \mathrm{r}=2,19)$.

A categoria desacreditado engloba respostas que fazem referências genéricas ao descrédito, preconceito e até desprezo com que é visto o psicólogo: "A imagem é péssima e preconceituosa"; "Acho que despreza, por dar um enorme valor ao médico"; "Descrença total na maioria. Mas aparentemente o conceito do psicólogo tem melhorado um pouquinho". A análise estatística não rejeita a hidótese nula de estabilidade $(r=0,63 ; t=2,15)$

Menos freqüente, aparecendo uns anos sim, outros não, temos a categoria "Amigo pago", que atribui ao psicólogo um conhecimento do senso comum.

Com relação às respostas que se referem ao que o psicólogo faz, temos três subcategorias: a primeira, invasor e temor de invasão reúne as respostas que definem a atividade do psicólogo como sendo a de um invasor da privacidade ou despertando tal temor: "Abelhudo"; "É aquele intrometido que adora fazer perguntas";

\begin{tabular}{|c|c|c|c|c|c|c|c|c|c|c|c|}
\hline \multicolumn{12}{|c|}{$\begin{array}{c}\text { TABELA 5 } \\
\text { DIMENSÃO CAMPO DE REPRESENTAÇĀO: PORCENTAGEM } \\
\text { DE CONCEITUAÇŌES (OBJETIVAÇŌES) } \\
\text { ASSOCIADAS A VALORAÇŌES POSITIVAS }\end{array}$} \\
\hline$\frac{1000 / 2}{a^{2}} / 2^{c}$ & Caracteristicas Positivas & 76 & 77 & 78 & 79 & 80 & 81 & 82 & 83 & 84 & Total \\
\hline \multirow{4}{*}{ 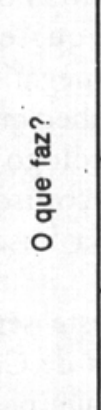 } & $\begin{array}{l}\text { Super-poderes para } \\
\text { solucionar problemas }\end{array}$ & 18 & 47 & 32 & 42 & 29 & 53 & 38 & 21 & 40 & 35 \\
\hline & \multirow{2}{*}{$\begin{array}{l}\text { Soluciona problemas } \\
\text { Necessário para solucionar } \\
\text { problemas específicos }\end{array}$} & 65 & 21 & 45 & 58 & 67 & 20 & 46 & 50 & 40 & 46 \\
\hline & & 12 & 5 & 5 & 0 & 0 & 0 & 8 & 14 & 7 & 5 \\
\hline & $\begin{array}{l}\text { Solucionar os próprios } \\
\text { problemas }\end{array}$ & 0 & 0 & 0 & 0 & 5 & 13 & 8 & 0 & 0 & 3 \\
\hline \multirow{5}{*}{ 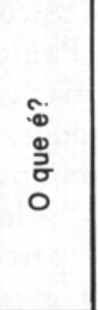 } & \multirow{3}{*}{$\begin{array}{l}\text { Inteligente } \\
\text { Seguro } \\
\text { Paciente }\end{array}$} & 0 & 11 & 0 & 0 & 0 & 7 & 0 & 0 & 0 & 2 \\
\hline & & 6 & 5 & 9 & 0 & 0 & 7 & 0 & 0 & 7 & 4 \\
\hline & & 0 & 0 & 9 & 0 & 0 & 0 &, 0 & 14 & 0 & 3 \\
\hline & \multirow{2}{*}{ Honesto } & 0 & 5 & 0 & 0 & 0 & 0 & 0 & 0 & 0 & 1 \\
\hline & & 0 & 5 & 0 & 0 & 0 & 0 & 0 & 0 & 7 & 1 \\
\hline
\end{tabular}

"Muitos têm até medo de conversar com psicólogos com o receio de estarem sendo analisados"; "O público tem medo de falar com psicólogo, com receio que este descubra algo de sua vida". Esta categoria diminuiu significativamente com o tempo $(r=-0,80 ; t=53)$.

A segunda subcategoria, medo da loucura, reúne referências do tipo: "Infelizmente, para eles os psicólogos tratam de loucos e por isso muitas vezes o indivíduo evita, mesmo que necessário, procurar um psicólogo por causa deste preconceito"; "Eles resistem a procurar um, se preciso, porque acham que isso é para loucos"; "A maioria tem um grande preconceito, 'eu não sou louco', não preciso contato com psicólogo". Foi encontrada estabilidade no tempo $(r=-0,58 ; t=1,89)$.

Finaimente, a terceira subcategoria, menos freqüente que as anteriores, manipulador c temor da dependência, engloba respostas que indicam que "O psicólogo é alguém que se intromete na sua vida e tenta moldá-lo"; "O psicólogo vai criar em cima do paciente uma relação de dependência"; "Ir a um psicólogo é sinal de fraqueza".

Vejamos agora como é o psicólogo. A descrição mais freqüente e re- corrente, em todos os anos analisados, é a que afirma ser o psicólogo louco, pirado, encucado, anormal, desequilibrado, diferente: "Sinceramente, o psicólogo é visto como um maluco problemático que, além de seus problemas, ainda quer resolver os dos outros"; "O psicólogo é visto como um indivíduo cheio de problemas que não tem capacidade de resolver o problema de ninguém"; "Geralmente como um 'ser' estranho e muitas vezes ouve-se dizer 'todo psicólogo é louco". Esta categoria apresentou estabilidade no tempo. $(r=0,13$; $t=0,35$ ).

As três outras categorias restantes aparecem esporadicamente e descrevem, respectivamente, "aquela chata do colégio", atribuem características de frieza e desumanidade ao psicólogo ("Pessoa essencialmente fria, desumana, voltada aos problemas numa relação sádica, sem campo de ação definido...") e de indecisão ("Pessoa que fez psicologia porque não sabia o que fazer").

A imagem positivamente valorizada do psicólogo (Tabela 5) não contém referências ao aspecto do conhecimento, mas tão somente à prática e características pessoais.

Um exame da Tabela 5 mostra uma variação na atuação do psicóloPSICOLOGIA, CIÉNCIA E PROFISSÃO, 33 
go, desde a capacidade quase mágica para solucionar problemas alheios até a capacidade de solucionar apenas os próprios. Sob a rubrica de superpoderes foram reunidas afirmaçōes do tipo "O psicólogo é mistificado como uma pessoa que tem o dom de entender e curar tudo e todos"; "Uma imagem de salvador dos homens". Foi encontrada estabilidade no tempo $r=0,13 ; \mathbf{t}=0,35$ ).

A categoria que concentra maior número é a que contém respostas que simplesmente afirmam a capacidade de resolver os problemas das pessoas: "Um resolvedor dos problemas dos outros"; "Uma pessoa a quem recorrer para resolver problemas".

As duas subcategorias restantes são bem menos frequientes e referemse: à necessidade de se recorrer ao psicólogo em certas ocasiões, como "Resolver os problemas do filho que repete o ano na escola" ou, ainda, "Só é util para cuidar de loucos ou algúem com problemas muito sérios"; e à solução dos próprios problemas, como capacitar as mulheres a "Cuidar dos filhos e coisas do gềnero".

Finalmente, as atribuições de características pessoais, como no caso das apontadas como negativas, são pouco freqüentes e mencionam os atributos: seguro, inteligente, paciente, honesto e digno de admiração, em frases como "A imagem de uma pessoa segura, que compreende, que tem um saco enorme e que sabe dar consethos"; "Uma pessoa muico inteligente, capaz de saber tudo o que pensamos". Não foi feita análise estatística desses dados.

\section{Discusas̃o}

O conteúdo das informações, transmitidas pelos sujeitos desta pesquisa, que mostram que a psicologia é conhecida principalmente como psicologia clínica, não discrepa do que realmente acontece em nosso meio. Desde as pesquisas de Mello (1975) e Carvalho e Kavano (1982), entre outras, sabe-se da marcada preferência, por parte dos que cursam psicologia, por esta área de atuação.

Também o fato de ocupar um espaço entre outras profissões e a aproximação principalmente da psiquiatria são fatos explicáveis. A atuação na área clínica torna plausível a aproximação da psiquiatria. Se a análise das informaçōes coletadas se restringisse a este aspecto, os resultados do trabalho poderiam até ser considerados gratificantes, dado o prestigio da medicina em nosso meio. Mas o fato de se ter encontrado que quase dois terços das avaliaçōes são negativas $\mathrm{e}$ que as referências ao conhecimento, prática e pessoa do psicólogo são, para dizer o mínimo, pouco lisonjeiras, merece reflexão e uma busca de explicação.

Uma primeira pista neste sentido foi fornecida pela pesquisa de Carvalho e Kavano (1982), que permite conhecer a perspectiva dos psicólogos recém-formados em São Paulo, no que concerne a sua opção maciça pela atuação em clínica. Segundo as autoras, os psicólogos são atraídos pela natureza dessa atividade, "pelo fato desse tipo de trabalho ser percebido como uma relaçāo direta e intima com pessoas, e uma relação de aju$\mathrm{da}$ ". Continuam as autoras: "...o modelo que estas justificativas expressam é a atuaçāo terapêutica, principalmente no modelo de psicoterapia individual prolongada"... "ajuda" aqui tem uma conotação muito específica, a de aliviar sofrimento psicológico, angústias, etc". (p. 10; grifos no original). $\mathrm{E}$ mais adiante: "O que a atuação clínica oferece aos psicólogos, portanto, e que tanto os atrai, parece ser a possibilidade de penetrar no outro, conhecê-lo, estabelecer com ele um certo tipo de relação" (p. 11; grifo nosso). Além da justificativa pela natureza da atividade, as autoras consideram ainda "a importância das justificativas referentes a condições pessoais para a opção pela clínica, condiçōes essas que, com poucas exceções, consistem em "vocaçāo" ou "jeito" para o trabalho... parece-nos que este tipo de justificativa expressa, não propriamente uma posição teórica a respeito dessa questão, mas sim uma visāo leiga e relativamentc ingênua sobre a natureza do trabalho clínico" (p.12; grifos nossos).

O que estas observaçōes sugerem é que a imagem do leigo, detectada na presente pesquisa, não é fruto de geração espontânea. Todavia, como aponta Moscovici (1976), as representaçōes não são mero reflexo de um objeto ou conjunto de idéias geradas no contexto da ciência, mas são fruto de um processo ativo, pelo qual os dados são reconstruídos em um contexto de associaçōes, valores etc.

$O$ resultado deste processo ativo, como se viu, foi representar a relação intima e direta, de ajuda, como invasão indevida de privacidade, que permite 'radiografar' a mente das pessoas, devassar segredos, criar dependência. $E$, na medida em que esta relaçāo é mediada pelo dom, pela intuição, jeito e não baseada em algo racional, compreensível e transmissí. vel, o psicólogo passa a ser aproximado de outras categorias sociais que reclamam para si dons e funçōes semelhantes. Também nāo é favorável a aproximação da psiquiatria, pois a palavra médico vem quase sempre acompanhada de aspas e psiquiatra vem precedida de 'sub' ou 'secretário de'. E tudo isto se volta como um bumerangue contra a pessoa do psicólogo, que é raxado de abelhudo, louco, pirado, encucado e, ainda mais, desonesto, pois cobra caro por serviços que não sāo tão especializados assim. $\hat{E}$ um 'amigo pago' ou, na pior da hipóteses, 'charlatão esfaqueador de bolsos da elite fútil'. $\mathrm{E}$, mais uma vez, tem-se que concordar com Moscovici (1976), o veredicto precede o julgamento: se as coisas são assim, é arriscado experimentar!

Não parece impróprio, mesmo considerando as diferenças de objeto e contexto, comparar nossos resultados com os obtidos por Moscovici (1976) acerca da imagem do psicanalista na França, dadas as semelhanças que serão apontadas a seguir $e$ as interpretaçōes oferecidas pelo autor.'

As aproximações são praticamente as mesmas. O psicanalista é aproximado do médico (45\%), do psicólogo $(51 \%)$, do padre (13\%), não faltando até menção ao mágico (pp. 155-156). Novas semelhanças surgem quando o autor discute os critérios usados pelos sujeitos para organizar a imagem do psicanalista. A normalidade é ilustrada por frases que soam muito familiares: "É um ser normal como os ou-

10 autor indica que șa dados oferecidos pela classe média e estudantes. Informa rambxin que, em $47 \%$ dos casos, a representaçāo do psicanalista é neutra, em $29 \%$ é positiva, em $11 \%$ é negativa e em $11 \%$ nāo houve imagem. 


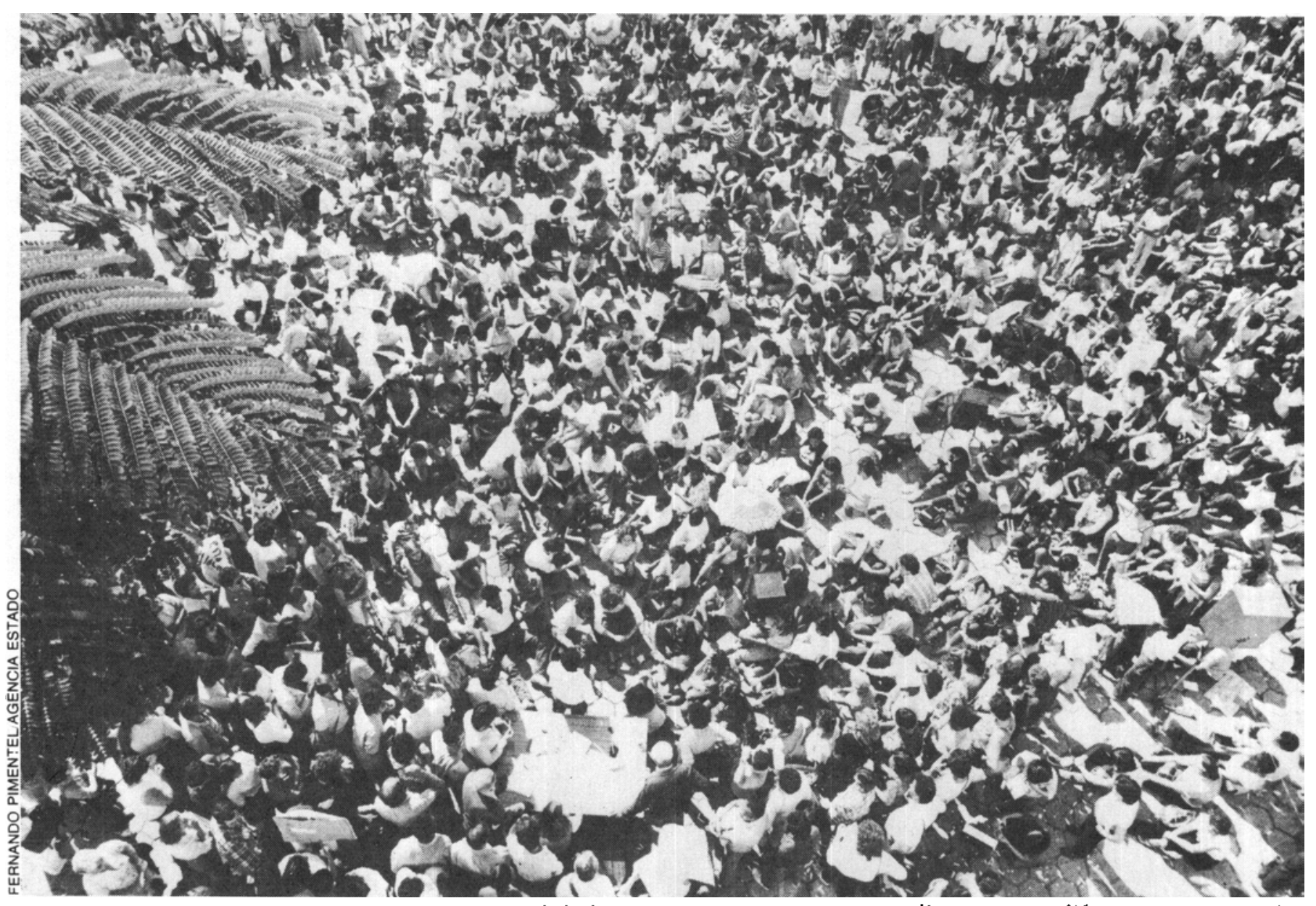

tros"; "Uma espérie de louco por viver entre anormais"; "Eu o vejo como um homem perigoso, que deve ser preso; sendo louco, julga os outros por si e, quanto menos louco se é, mais julga que se está perturbado" (p. 162). Comenta o autor: "A figura do psicanalista, ora aparece rodeada de um halo de sabedoria e equilíbrio, ora imersa em um mundo estranho e perigoso. Não é sua intenção se comunicar com seus doentes? Devido a isto, pode tanto permanecer equilibrado, como ser conraminado por eles, a não ser que tente generalizar seus próprios problemas" (p. 163). O leiror deve julgar a adequação destas observaçōes aos dados desta pesquisa.

Mas as semelhanças não param por aí. Referindo-se ao outro critério, os atributos profissionais, além daqueles de um médico um tanto especial, de um filósofo, humanista, o autor identifica ainda uma exigência de vocação, abnegação e pureza de in. tenção, que deve existir em sua relação com o cliente. E, a par desta elevada exigência moral, o autor encontra a acusação de charlatanismo. $E$ oferece as seguintes ponderações.
As qualidades exigidas visam a contrabalançar a inquietação que sua atividade desperta: "(ele) detém um poder inquietante, pois pode influir sobre o destino dos indivíduos e a sociedade não tem qualquer meio de controlar sua ação" (p.163). O charlatanismo está ligado à questão do dinheiro e assume várias significações. O psicanalista é acusado de ser um simulador, criador de ilusāo, pois joga um jogo em que nāo acredita, visando a ganhar dinheiro ou exercer influência. "Paga-se caro para que ele dê a impressão de ser um amigo ..." (. 163). Ou, ainda, torna a "psicanálise moda passageira, de sorte que o psicanalista precisa extorquir o máximo de dinheiro possível em um breve lapso de tempo de sua clientela de snobs ricos". Finalmente, o dinheiro mancha a relação, pois "esta troca dinheiro-afetividade é uma troca heterogênea, sem equivalente possível, ao mesmo tempo insatisfatória, desvalorizada, proibida" (p. 164). Não há, como no caso do médico, a legitimação do pagamento pela prescrição de uma receita.

Finalmente, nāo se pode deixar de salientar uma diferença entre os dados dos sujeitos franceses e os dos brasileiros. Aqueles fornecem indicações sobre o aspecto físico do psicanalista: é uma figura do sexo masculino, que lembra Freud (usa barba, óculos e é de idade madura, seu olhar é penetrante). Poder-se-ia pensar que a ausência deste tipo de descrição aqui se deve ao fato de a psicologia ter vários pais e a psicanálise, um só.

Para terminar, só mesmo lembrando o velho Guimarāes Rosa: "Cumprade meu Quelemen já dizia, viver é muito perigoso". Que o digam os psicológos!

\section{REFERENNCIAS BIBLIOGRÁFICAS}

CARvalho, A. M. A. e Kavano, E. A Justificastivas de opçảo por área de trabalho em psicologia: uma análise da imagem da profissão eri psicólogos recém-formados. Psicologia. 1982, 8 (3). 1-18.

MELLO, S.L. Psicologia e profissão em Säo Paulo. Sảo Paulo: Ática, 1975.

MOSCOVICI. S. La Psicanalyse, son image et son public. Paris: Presse Universiraire de France. MOSCOVICl, S.The phenomenon of social repre. sentations. Em R. M. Farr e S. Moscovici (Orgs). Social representations. Cambridge: Cambridge University Press, 1981, pp. 3.69.

PSICOLOGIA, CIÉNCIA E PROFISSĀO. 35 